\title{
Comment
}

\section{Being creative in a greenhouse: art and global warming}

\author{
Donato Ramani
}

They say that artists are the "antennae of society". For the sake of precision, this definition belongs to Marshall McLuhan, a much acclaimed Canadian sociologist who provided key insights on communication issues, old and new media of communication and the impact they have on the life individuals, communities, and of the new "global village", in a now small world produced by new technologies.

The world has actually become a small world. Not only owing to TV, satellites and the Internet that allow us to jump from side to side of our planet in a click. We will borrow the definition of the artist from McLuhan to adapt it to another phenomenon where the word "global" has an equally important meaning. A phenomenon that evokes dry lands, devastating rains, tsunamis and hurricanes, torrid summers and melting glaciers, icebergs leaving their millenary locations to embark on a journey without return. "Global warming", that's its name. We have already spotted its effects here and there. Certainly we have heard of it so many times in the past few years that the apocalyptic landscape described above has now the dull flavour of a déjà-vu. We have read of it many times on newspapers, books, on the Internet. We have heard scientists, politicians, members of environmentalist associations talking. Recently, having received an Oscar and a Nobel prize for his awareness-raising work on the risks of the greenhouse effect, a nearly-elected American president has become a much acclaimed activist. But in the past few years, this debate has been seeing the voice of the artists joining the others. This should not surprise that much, also in the light of McLuhan's words. GMOs, biotechnologies, neurosciences, robotics, electronics, privacy, health, environment. The world and the public opinion are debating on the capital scientific issues having such a large impact on our society. Artists live within this very society, becoming interpreters of it, based on their sensibility, culture, history, interests, instruments. And sometimes they even snatch the tools from the scientists' hands, to build works of art that are also works of science. And they are, more or less consciously, works of science communication. Informal communication? Yes. Not traditional at all? No, totally outside the norms. But often effective. As demonstrated by the assortment of events, festivals, museums, scientific contests which ever more frequently host works of art.

A boom that also regards ecology and climate changes. Each artist with their personal interpretation. Some artists such as Katerina Gutierrez, Chilean, and Alessandro Ricci, Italian, paint their pictures with smog collected through filtered air in the cities or from monuments and windowsills. Some other artists use Photoshop to create new animals undergoing a hasty evolution to adapt to the deep and fast environmental changes. This is the case of the American artist Rebecca Di Domenico (www.didomenicostudio.com). There are those such as the Cape Farewell group (www.capefarewell.com) that embark on a boat to reach the Arctic. Artists, scientists and popularisers, all together for scientific and creative explorations. "We engage artists for their ability to evolve and amplify a creative language, communicating on a human scale the urgency of the global climate challenge [...] One salient image, sculpture or event can speak louder than volumes of scientific data and engage the public's imagination in an immediate way", to quote the website of the organisation.

Hence, popularising artists are aware of their role and of the considerable communication potential of the artistic medium. This commentary and these papers will gather their voices, to understand their motivations, objectives and the perception they have of their own work. We will also investigate the origins of the change in the relation of the artists with the environment, trying to understand how in the past few decades artistic experimentation has shifted its focus "on the change in life, in the whole society and in the entire ecological context". And we will listen to the words of the managers of organisations that constantly deal with art and science. In some cases, such as The Canary Project (www.canary- 
project.org), they were created especially to investigate the artistic potential in the debate and in the communication on the green house effect.

Some may give these initiatives the cold shoulder, thinking they are an overstatement. Art may be seen, in this context, as an exotic seasoning, certainly a savoury one, but hardly anything other than "fashionable". This is the role of art and of the artist taken to the extreme within an extremely important and serious debate, whose players move across totally different grounds. And yet, those who deal with science communication will hardly be left untouched by the words of Andrea Polli (www.andreapolli.com), an American artist, who in her contribution tells about the multi-year experience side by side with atmosphere scientists, to understand how to disseminate at best, through her works of art, information on climate and atmosphere. And she tells about her journey on the Antarctic ice, made "to find a better way to engage the public in the issues of the global warming". Even there, among the ice of the South Pole, side by side with scientists. But with a completely new informative and communicating approach and probably aware that, as Albert Einstein once said, "You cannot solve a problem with the same thinking that caused the problem".

\section{Author}

Donato Ramani currently holds a research fellowship at the Multidisciplinary laboratory for natural and human sciences of SISSA-ISAS of Trieste. As a free-lance author, he works with a number of Italian journals to write on science, new technologies and arts. Along with Alessandra Drioli, he is a co-author of the book Vietato non toccare (Springer 2008), on the utilization of art in science museums.

E-mail: ramani@sissa.it. 